Research Article

\title{
Comparison of two different doses of dexmedetomidine infusion on post- operative pain and sedation in patients undergoing laparoscopic surgery
}

\author{
Tanmay Tiwari*
}

\begin{abstract}
Department of Anesthesia, LLRM Medical College, Meerut, Uttar Pradesh, India

Received: 30 September 2014 Accepted: 17 October 2014

*Correspondence to:

Dr. Tanmay Tiwari, Email: tanmayanesthesia@ gmail.com
\end{abstract}

Copyright: (C) the author(s), publisher and licensee Medip Academy. This is an openaccess article distributed under the terms of the Creative Commons Attribution NonCommercial License, which permits unrestricted noncommercial use, distribution, and reproduction in any medium, provided the original work is properly cited.

\begin{abstract}
Background: Effective attenuation of the sympathoadrenal stress responses is an important goal in anesthesiology. Dexmedetomidine (Dex) a new generation highly selective $\alpha 2$ adrenoreceptor agonist might permit sedation and analgesia without the unwanted vascular effects from activation of $\alpha 1$ receptors. In addition, it has been shown to induce a centrally mediated reduction of sympathetic nervous system activity and decrease hemodynamic and plasma catecholamine response to stressful events. These properties theoretically make it a suitable agent for use as part of the anesthetic regimen. The aim was to study the effect of Dex infusion at two different doses on sedation and post-operative pain using Ramsay sedation score and visual analog scale (VAS) during the post-operative period for first $24 \mathrm{hrs}$.

Methods: In this study, the patients were randomly divided into three different groups (control, Dex 0.3, and Dex 0.6) using computer generated random table. Post-operatively patient's sedation pain scores were compared using Ramsay sedation score and VAS, respectively.

Results: It was observed that the duration of surgery, duration of infusion and use of fentanyl $(\mu \mathrm{g})$ was statistically insignificant in all the three groups. The mean pain in subjects of both Dex 0.3 and Dex 0.6 just after surgery till 6 hrs post-surgery were found to be significantly $(\mathrm{p}<0.01)$ lower when compared to control while in other periods it did not differed significantly $(\mathrm{p}>0.05)$ between the three groups i.e., remains statistically the same. On comparing the mean Sedation in subjects of Dex 0.3 and Dex 0.6 just after surgery till $12 \mathrm{hrs}$ post-surgery were found to be significantly $(p<0.05$ or $p<0.01)$ higher when compared to Control. Further, the mean Sedation in subjects of Dex 0.6 just after surgery and 2 hrs after surgery were also found to be significantly $(\mathrm{p}<0.01)$ higher than that of Dex 0.3 . However, the mean sedation in all three groups at $18 \mathrm{hrs}$ after surgery and $24 \mathrm{hrs}$ after surgery remains the same i.e., did not differed significantly $(\mathrm{p}>0.05)$.

Conclusion: The perioperative infusion of Dex may be an attractive option during laparoscopic surgery as it, offered better control of intraoperative and post-operative hemodynamics, and decreased post-operative pain level and better sedation scores, as compared with control.
\end{abstract}

Keywords: Dexmedetomidine, Sedation, Pain, Laparoscopic surgeries

\section{INTRODUCTION}

Dexmedetomidine (Dex), an imidazole compound, is the pharmacologically active dextroisomer of medetomidine that displays specific and selective $\alpha_{2}$-adrenoceptor agonism. The mechanism of action is unique and differs from those of currently used sedative agents, including clonidine. Activation of the receptors in the brain and spinal cord inhibits neuronal firing, causing hypotension, bradycardia, sedation, and analgesia. The responses to activation of the receptors in other areas include decreased salivation, decreased secretion, and decreased bowel motility in the gastrointestinal tract; contraction of vascular and other smooth muscle; inhibition of renin release, increased glomerular filtration, and increased secretion of sodium and water in the kidney; decreased intraocular pressure; and decreased insulin release from the pancreas. ${ }^{1}$ In general, presynaptic activation of the $\alpha_{2}$-adrenoceptor inhibits the release of norepinephrine, terminating the propagation of pain signals. Postsynaptic activation of $\alpha_{2}$-adrenoceptors 
in the central nervous system (CNS) inhibits sympathetic activity and thus can decrease blood pressure and heart rate (HR). Combined, these effects can produce analgesia, sedation, and anxiolysis. Dex combines all these effects, thus avoiding some of the side-effects of multiagent therapies.

One of the highest densities of $\alpha_{2}$ receptors has been detected in the locus coeruleus, the predominant noradrenergic nucleus in the brain and an important modulator of vigilance. The hypnotic and sedative effects of $\alpha_{2}$-adrenoceptor activation have been attributed to this site in the CNS. ${ }^{2}$ The locus coeruleus is also the site of origin for the ascending and descending medullospinal noradrenergic pathway, known to be an important modulator of nociceptive neurotransmission. In addition to Dex 's action in the locus coeruleus of the brain stem, it has been shown to stimulate $\alpha_{2}$ receptors directly in the spinal cord, thus inhibiting the firing of nociceptive neurons. The substantia gelatinosa of the dorsal horn of the spinal cord contains receptors which, when stimulated, inhibit the firing of nociceptive neurons stimulated by peripheral $\mathrm{A} \delta$ and $\mathrm{C}$ fibers and also inhibit the release of the nociceptive neurotransmitter substance $\mathrm{P}^{3}$

\section{Aims and objectives}

To study the effect of Dex infusion at two different doses on sedation and post-operative pain using Ramsay sedation score and visual analog scale (VAS) during post-operative period for first $24 \mathrm{hrs}$.

\section{METHODS}

The present study was conducted at Chhatrapati Shahuji Maharaj Medical University, Lucknow, UP. Following inclusion and exclusion criteria was used to select the study subjects.

\section{Inclusion criteria}

- Patients aged 20-50 years belonging to ASA physical status I or II planned for laparoscopic surgery.

\section{Exclusion criteria}

- An allergy to $\alpha 2$ adrenergic agonist or antagonist

- A history of uncontrolled hypertension, heart block greater than first degree

- A history of alcohol or drug abuse

- Clinically significant neurologic, cardiovascular, renal, hepatic, or gastrointestinal diseases, and

- Pregnant or breast-feeding.

Thus using the above-mentioned inclusion and exclusion criteria 60 patients were selected for the study. After getting approval from Ethical Committee of the college, informed consent was taken from the patient.
The patients were randomly allocated to three different groups using the computer generated random table.

Group 1 (control): Received saline infusion during procedure.

Group 2 (Dex 0.3): Received infusion of Dex $0.3 \mu \mathrm{g} / \mathrm{kg} / \mathrm{hr}$. Group 3 (Dex 0.6): Received infusion of Dex $0.6 \mu \mathrm{g} / \mathrm{kg} / \mathrm{hr}$.

A baseline cardio-respiratory measures including HR, pulse oximetry $\left(\mathrm{SPO}_{2}\right)$, noninvasive systolic blood pressure (SBP), diastolic blood pressure (DBP), mean arterial pressure (MAP) and end tidal $\mathrm{Co}_{2}\left(\mathrm{Etco}_{2}\right)$ were recorded once the patient came to operating room. Patients were monitored continuously during the surgery. Duration of surgery, duration of infusion and use of fentanyl $(\mu \mathrm{g})$ were recorded. During the post-operative period of $24 \mathrm{hrs}$ patient was monitored at intervals of $2 \mathrm{hrs}$ for first $6 \mathrm{hrs}$ and then at interval of 6 hrs till 24 hrs, sedation using Ramsay sedation score, pain using VAS, incidence of post-operative nausea and vomiting and use of any drug for pain, vomiting and any other side effect.

\section{RESULTS}

A total of 60 patients $($ male $=20$ and female $=40)$ were randomized equally to treat either with control, Dex 0.3 and Dex 0.6. The age of all patients ranged from 20 to 50 years. The baseline demographic characteristics (sex age, weight, SBP, DBP, MAP, HR and ASA Grade) of three groups of patients were compared and it was observed that there was no statistically significant (Table 1).

It was observed that the duration of surgery was almost equal in control, Dex 0.3 and Dex 0.6 groups (88.75 mins, 87.75 mins and 88 mins, respectively). The duration of infusion in Control, Dex 0.3 and Dex 0.6 ranged from 70 to $130 \mathrm{mins}, 60$ to $130 \mathrm{mins}$ and 75 to $135 \mathrm{mins}$ respectively with mean \pm standard deviation $102.25 \pm 16.66$ mins, $99.75 \pm 18.60$ mins and $102.00 \pm 16.01$ mins, respectively. When the use of fentanyl was compared it was observed that in control and Dex 0.3 group it was nearly similar ( 58.75 and $59.25 \mu \mathrm{g}$, respectively). The mean use of Fentanyl was slightly higher in Dex $0.6(62 \mu \mathrm{g})$ when compared to both control and Dex 0.3. However, the difference in the fentanyl dose in the all the three groups was not statically significant (Table 2).

The level of pain (VAS) in subjects of three groups just after surgery till 24 hrs were summarized in Table 3 and also shown graphically in Figure 1. Table 3 and Figure 1 shows just after surgery, the mean pain in subjects of Dex 0.3 and Dex 0.6 were comparatively low as compared to control and remains lower till $24 \mathrm{hrs}$ and evident more in Dex 0.6 than Dex 0.3. On comparing the mean pain in subjects of three groups, the pain in subjects of both Dex 0.3 and Dex 0.6 just after surgery till 6 hrs post-surgery were found to be significantly $(p<0.01)$ lower as compared to control while 
in other periods, it did not differed significantly $(p>0.05)$ between the three groups i.e., remains statistically the same (Table 3).

The sedation scores in subjects of three groups just after surgery till $24 \mathrm{hrs}$ were summarized in Table 4 and also shown graphically in Figure 2. Table 4 and Figure 2 both shows just after surgery, the mean sedation in subjects of
Dex 0.3 and Dex 0.6 were comparatively high as compared to control and remains higher till $24 \mathrm{hrs}$ post-surgery and evident high in Dex 0.6 than Dex 0.3. On comparing the mean sedation in subjects of three groups, the sedation in subjects of Dex 0.3 and Dex 0.6 just after surgery till 12 hrs post-surgery were found to be significantly $(\mathrm{p}<0.05$ or $\mathrm{p}<0.01)$ higher as compared to control. Further, the mean sedation in subjects of Dex 0.6 just after surgery and 2 hrs

Table 1: Baseline summary of subjects of three groups.

\begin{tabular}{|lcc|c|c|}
\hline Characteristics & Control $(\mathbf{n}=\mathbf{2 0})$ & Dex $\mathbf{0 . 3}(\mathbf{n}=\mathbf{2 0})$ & Dex $\mathbf{0 . 6}(\mathbf{n}=\mathbf{2 0})$ & $\boldsymbol{\chi}^{\mathbf{2}} /$ ANOVA f value \\
\hline Sex (male/female) & $6 / 14$ & $8 / 12$ & $6 / 14$ & $0.60^{\text {ns }}$ \\
\hline Age (yrs) & $33.95 \pm 6.67$ & $34.20 \pm 10.75$ & $34.30 \pm 7.95$ & $0.01^{\text {ns }}$ \\
\hline Weight (kg) & $57.20 \pm 8.57$ & $61.00 \pm 11.21$ & $58.70 \pm 8.19$ & $0.83^{\mathrm{ns}}$ \\
\hline SBP $(\mathrm{mmHg})$ & $121.40 \pm 10.85$ & $128.50 \pm 12.28$ & $126.95 \pm 10.67$ & $2.19^{\mathrm{ns}}$ \\
\hline DBP (mmHg) & $82.55 \pm 7.10$ & $82.90 \pm 9.41$ & $83.20 \pm 6.35$ & $0.04^{\mathrm{ns}}$ \\
\hline MAP (mmHg) & $95.50 \pm 7.86$ & $98.10 \pm 8.38$ & $97.78 \pm 7.03$ & $2.62^{\mathrm{ns}}$ \\
\hline HR (beat/mins) & $81.65 \pm 8.36$ & $83.95 \pm 7.50$ & $81.75 \pm 4.25$ & $0.70^{\mathrm{ns}}$ \\
\hline ASA Grade (I/II) & $11 / 9$ & $13 / 7$ & $9 / 11$ & $1.62^{\mathrm{ns}}$ \\
\hline
\end{tabular}

ns: $p>0.05$, ns: Not significant, SBP: Systolic blood pressure, DBP: Diastolic blood pressure, MAP: Mean arterial pressure, HR: Heart rate, ASA: American Society of Anesthesiologists, Dex: Dexmedetomidine

Table 2: Distribution of patients according to duration of surgery, duration of infusion and use of fentanyl in subjects of three groups.

\begin{tabular}{|l|c|c|c|c|}
\hline Characteristics & Control $(\mathbf{n}=\mathbf{2 0})$ & Dex $\mathbf{0 . 3}(\mathbf{n = 2 0})$ & Dex 0.6 $(\mathbf{n}=\mathbf{2 0})$ & ANOVA F value \\
\hline Duration of surgery (mins) & $88.75 \pm 17.16$ & $87.75 \pm 19.63$ & $88.00 \pm 17.65$ & $0.02^{\text {ns }}$ \\
\hline Duration of infusion (mins) & $102.25 \pm 16.66$ & $99.75 \pm 18.60$ & $102.00 \pm 16.01$ & $0.13^{\text {ns }}$ \\
\hline Use of fentanyl $(\mu \mathrm{g})$ & $58.75 \pm 7.93$ & $59.25 \pm 8.16$ & $62.00 \pm 12.18$ & $0.66^{\text {ns }}$ \\
\hline
\end{tabular}

ns: $p>0.05$, ns: Not significant, Dex: Dexmedetomidine

Table 3: Pain just after surgery in subjects of three groups.

\begin{tabular}{|c|c|c|c|}
\hline Periods & Control $(n=20)$ & Dex $0.3(n=20)$ & Dex $0.6(n=20)$ \\
\hline Just after surgery & $6.00 \pm 1.03$ & $4.60 \pm 1.43^{* *}$ & $3.90 \pm 1.02 * *$ \\
\hline $2 \mathrm{hrs}$ after surgery & $5.95 \pm 0.94$ & $4.50 \pm 1.40 * *$ & $3.80 \pm 0.95 * *$ \\
\hline $4 \mathrm{hrs}$ after surgery & $5.85 \pm 0.93$ & $4.35 \pm 1.42 * *$ & $3.65 \pm 0.75 * *$ \\
\hline 6 hrs after surgery & $5.65 \pm 0.91$ & $4.15 \pm 1.18 * *$ & $3.40 \pm 1.31 * *$ \\
\hline 12 hrs after surgery & $3.50 \pm 0.76$ & $3.40 \pm 1.39$ & $3.05 \pm 1.32$ \\
\hline 18 hrs after surgery & $2.65 \pm 0.88$ & $2.40 \pm 0.82$ & $2.35 \pm 0.67$ \\
\hline 24 hrs after surgery & $2.00 \pm 0.56$ & $2.00 \pm 0.86$ & $1.90 \pm 0.64$ \\
\hline
\end{tabular}

${ }^{*} \mathrm{p}<0.05$ or ${ }^{* *} \mathrm{p}<0.01$ as compared to control, ${ }^{\S} \mathrm{p}<0.05$ or ${ }^{\S} \mathrm{p}<0.01$ as compared to Dex 0.3 , Dex: Dexmedetomidine

Table 4: Sedation just after surgery in subjects of three groups.

\begin{tabular}{|c|c|c|c|}
\hline Periods & Control $(n=20)$ & Dex $0.3(n=20)$ & Dex $0.6(n=20)$ \\
\hline Just after surgery & $1.40 \pm 0.50$ & $3.50 \pm 0.76^{* *}$ & $4.35 \pm 0.75^{* * \S \S}$ \\
\hline $2 \mathrm{hrs}$ after surgery & $1.45 \pm 0.51$ & $3.35 \pm 0.75^{* *}$ & $4.00 \pm 0.86^{* * \S \S}$ \\
\hline 4 hrs after surgery & $1.50 \pm 0.51$ & $3.10 \pm 0.72 * *$ & $3.50 \pm 0.83 * *$ \\
\hline 6 hrs after surgery & $1.60 \pm 0.50$ & $2.85 \pm 0.37 * *$ & $2.95 \pm 0.69 * *$ \\
\hline 12 hrs after surgery & $1.80 \pm 0.41$ & $2.30 \pm 0.57^{*}$ & $2.47 \pm 0.41 * *$ \\
\hline 18 hrs after surgery & $1.75 \pm 0.44$ & $2.05 \pm 0.22$ & $2.10 \pm 0.31$ \\
\hline 24 hrs after surgery & $1.90 \pm 0.31$ & $2.15 \pm 0.37$ & $2.19 \pm 0.22$ \\
\hline
\end{tabular}

${ }^{*} \mathrm{p}<0.05$ or ${ }^{* *} \mathrm{p}<0.01$ as compared to control, ${ }^{\S} \mathrm{p}<0.05$ or ${ }^{\S} \mathrm{p}<0.01$ as compared to Dex 0.3 , Dex: Dexmedetomidine 


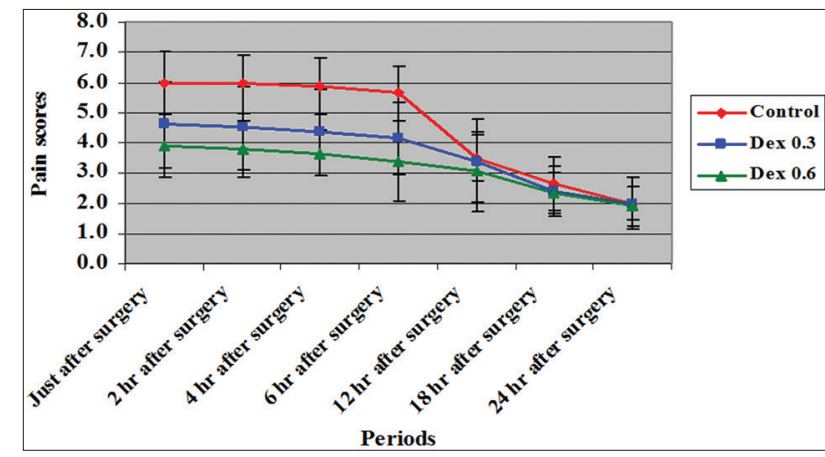

Figure 1: Mean ( \pm standard deviation) pain in subjects of three groups just after surgery.

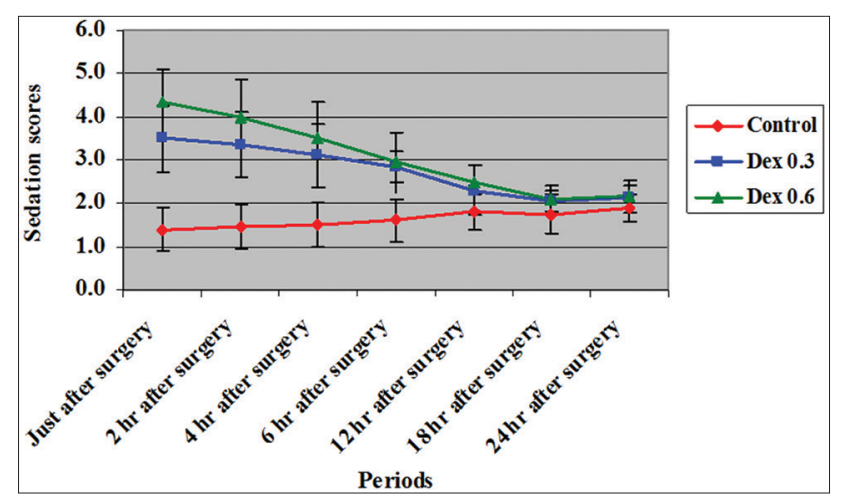

Figure 2: Mean ( \pm standard deviation) sedation in subjects of three groups just after surgery.

after surgery were also found to be significantly $(p<0.01)$ higher than that of Dex 0.3. However, the mean Sedation in all three groups at $18 \mathrm{hrs}$ after surgery and $24 \mathrm{hrs}$ after surgery remains the same i.e., did not differ significantly ( $>0.05)$ (Table 4).

\section{DISCUSSION}

In this study, we observed the effects of continuous perioperative infusion of Dex in two different doses of $0.3 \mu \mathrm{g} / \mathrm{kg} / \mathrm{hr}$ and $0.6 \mu \mathrm{g} / \mathrm{kg} / \mathrm{hr}$ on post-operative pain and sedation in patients undergoing laparoscopic surgeries.

In our study, 60 patients were randomly allocated to 3 different groups using computer-generated random number table. The three groups control, Dex 0.3, Dex 0.6 were similar to each other on demographic characteristics (age, sex, weight, ASA grade) and baseline hemodynamic parameters (SBP, DBP, MAP, HR) $\mathrm{p}>0.05$.

In the post-operative period of $24 \mathrm{hrs}$ on comparing the mean pain in subjects of three groups just after surgery till 24 hrs, pain in subjects of both Dex 0.3 and Dex 0.6 just after surgery and up to $6 \mathrm{hrs}$ after surgery were found to be significantly $(\mathrm{p}<0.01)$ lower as compared to control while in other periods it did not differed significantly ( $p>0.05$ ) between the three groups i.e. remains statistically the same. The failure of Dex to produce a sustained opioid sparing effect in the later post-operative periods was probably related to its short elimination half-life of $2 \mathrm{hrs}$. The ability of Dex to decrease anesthesia requirements, better control of heart rate and blood pressure, and provide analgesia without respiratory depression has been reported before. ${ }^{4-6}$ When infused at rates of 0.2 and $0.7 \mu \mathrm{g} / \mathrm{kg} / \mathrm{hr}$, Dex produced clinically effective sedation and reduced the analgesic requirements of ventilated intensive care unit patients. ${ }^{7}$ Aho et al.; 1991 showed that, after laparoscopic tubal ligation, Dex relieved pain and reduced opioid requirements. In our study, we gave fentanyl to all three groups in a dose of $1 \mu \mathrm{g} / \mathrm{kg}$ at the time of induction and compared the post-operative pain and sedation scores. ${ }^{8}$ Gurbet et al. 2006 published the results of a prospective, randomized, double-blinded study that continuous intravenous Dex during abdominal surgery provides effective post-operative analgesia, and reduces post-operative morphine requirements without increasing the incidence of side effects. ${ }^{9}$

\section{CONCLUSION}

Thus we conclude that the perioperative infusion of Dex has good efficacy during laparoscopic surgery as it, offered decreased postoperative pain level and better sedation scores as compared with control.

Funding: No funding sources

Conflict of interest: None declared

Ethical approval: The study was approved by the Institutional Ethics Committee

\section{REFERENCES}

1. Metz SA, Halter JB, Robertson RP. Induction of defective insulin secretion and impaired glucose tolerance by clonidine. Selective stimulation of metabolic alphaadrenergic pathways. Diabetes. 1978;27(5):554-62.

2. Hayashi Y, Maze M. Alpha 2 adrenoceptor agonists and anaesthesia. Br J Anaesth. 1993;71(1):108-18.

3. Kuraishi Y, Hirota N, Sato Y, Kaneko S, Satoh M, Takagi H. Noradrenergic inhibition of the release of substance $\mathrm{P}$ from the primary afferents in the rabbit spinal dorsal horn. Brain Res. 1985;359(1-2):177-82.

4. Arain SR, Ruehlow RM, Uhrich TD, Ebert TJ. The efficacy of dexmedetomidine versus morphine for postoperative analgesia after major inpatient surgery. Anesth Analg. 2004;98(1):153-8.

5. Dutta S, Karol MD, Cohen T, Jones RM, Mant T. Effect of dexmedetomidine on propofol requirements in healthy subjects. J Pharm Sci. 2001;90(2):172-81.

6. Thornton C, Lucas MA, Newton DE, Doré CJ, Jones RM. Effects of dexmedetomidine on isoflurane requirements in healthy volunteers. 2: auditory and somatosensory evoked responses. Br J Anaesth. 1999;83:381-6.

7. Bhana N, Goa KL, McClellan KJ. Dexmedetomidine. Drugs. 2000;59(2):263-8.

8. Aho M, Scheinin M, Lehtinen AM, Erkola O, Vuorinen J, Korttila K. Intramuscularly administered dexmedetomidine 
attenuates hemodynamic and stress hormone responses to gynecologic laparoscopy. Anesth Analg. 1992;75(6):932-9.

9. Gurbet A, Basagan-Mogol E, Turker G, Ugun F, Kaya FN, Ozcan B. Intraoperative infusion of dexmedetomidine reduces perioperative analgesic requirements. Can J Anaesth. 2006;53(7):646-52 doi: $10.5455 / 2319-2003 . i j b c p 20141220$

Cite this article as: Tiwari T. Comparison of two different doses of dexmedetomidine infusion on post-operative pain and sedation in patients undergoing laparoscopic surgery. Int J Basic Clin Pharmacol 2014;3:1052-6. 